Supporting Information

\title{
Characterizing Native and Hydrocarbon-stapled Enfuvirtide Conformations with Ion Mobility Mass Spectrometry and Hydrogen/Deuterium Exchange
}

Bradley B. Stocks ${ }^{1 *}$, Gregory H. Bird ${ }^{2}$, Loren D. Walensky², and Jeremy E. Melanson ${ }^{1}$

${ }^{1}$ National Research Council Canada, Metrology

1200 Montreal Road, Ottawa, Ontario, Canada K1A OR6

${ }^{2}$ Dana-Farber Cancer Institute

450 Brookline Avenue, Boston, Massachusetts, USA 02215

* Corresponding author: bradley.stocks@nrc-cnrc.gc.ca 


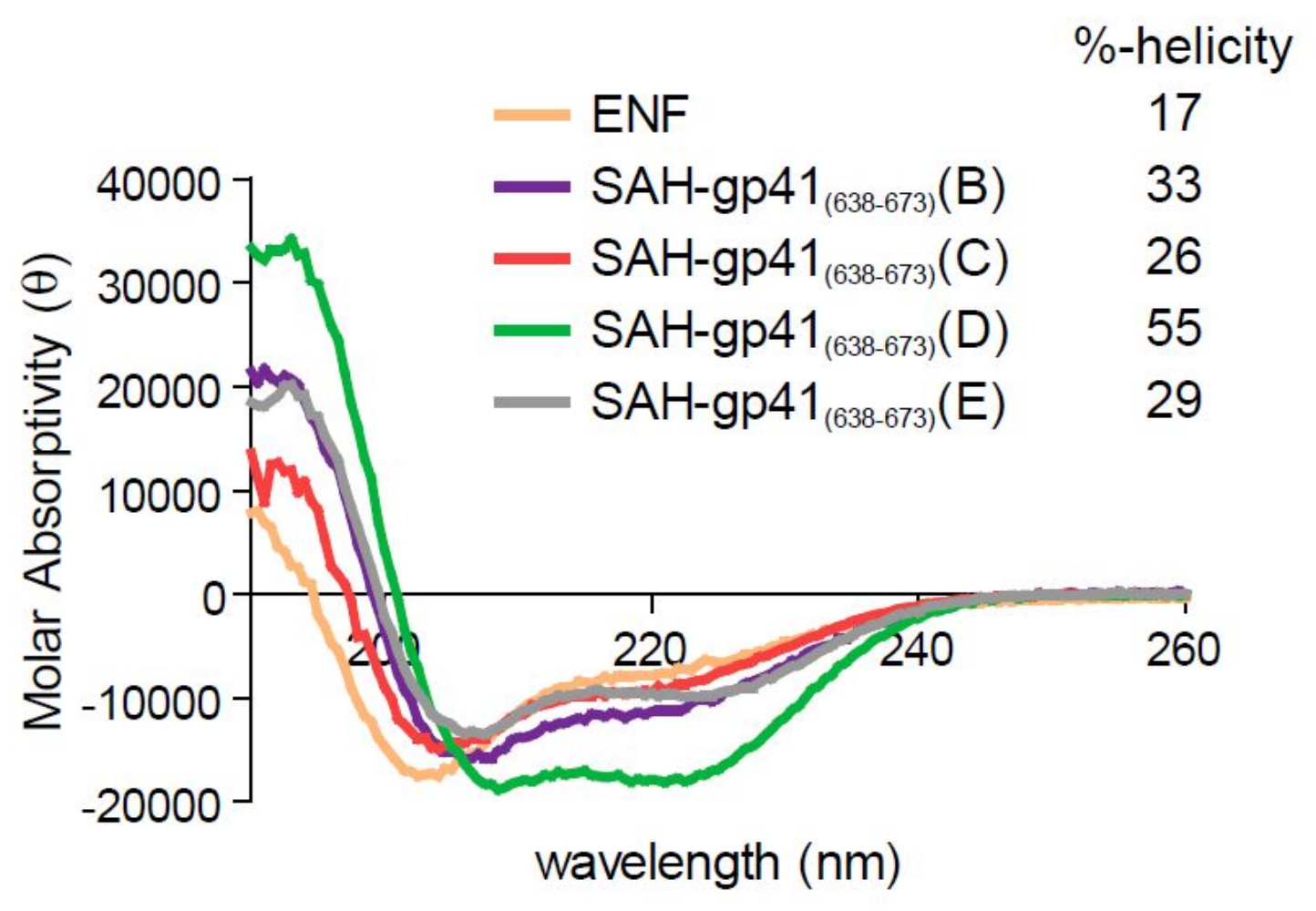

Figure S1. Circular dichroism spectra of native ENF and four single-stapled constructs. Percent helicity was calculated based on the theoretical maximum for a 36-residue peptide. 


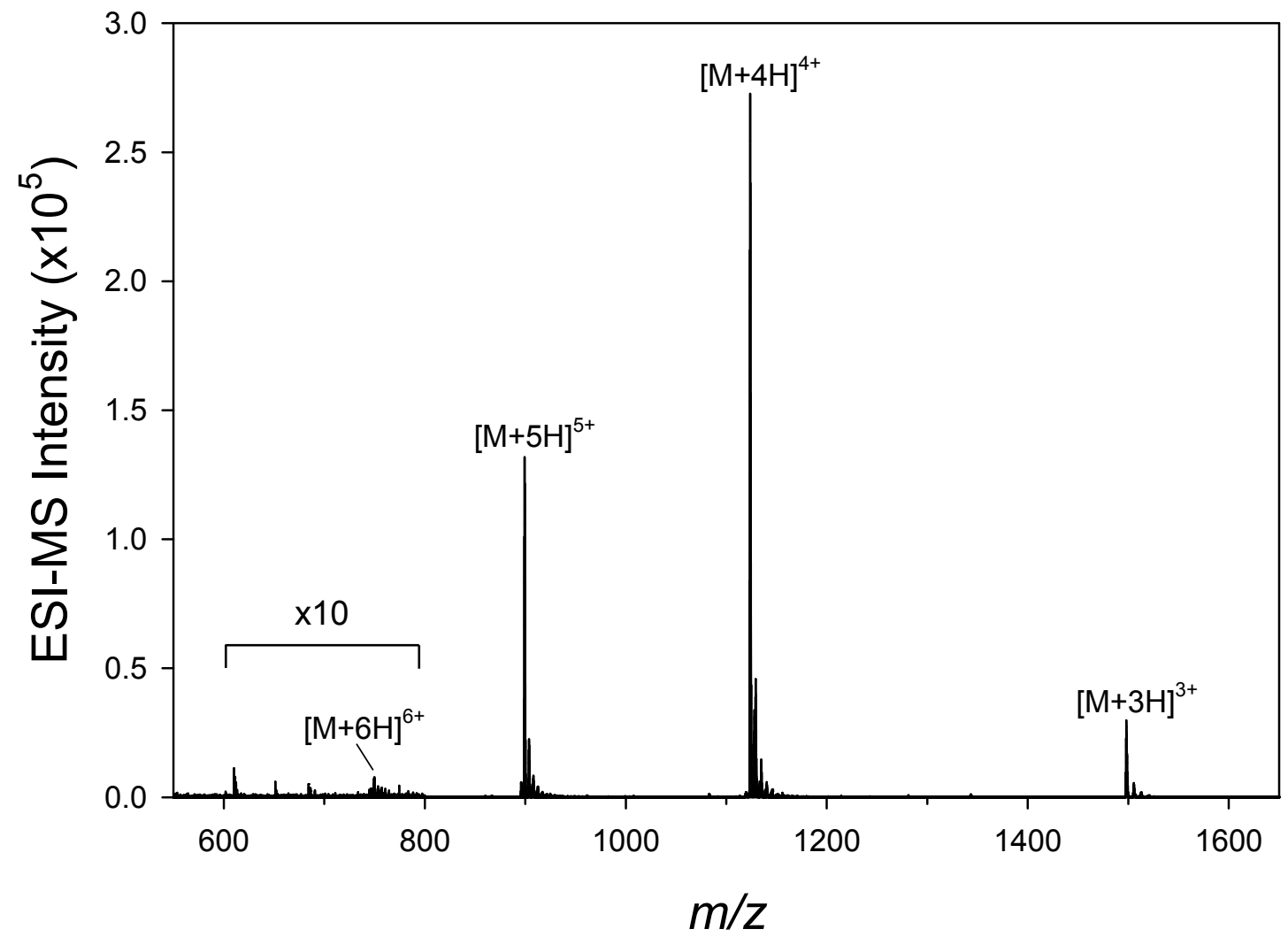

Figure S2. ESI-MS spectrum of enfuvirtide infused from $10 \mathrm{mM}$ ammonium acetate. To visualize the $6+$ charge state, the $m / z$ range from $600-800$ has been magnified 10 -fold. 


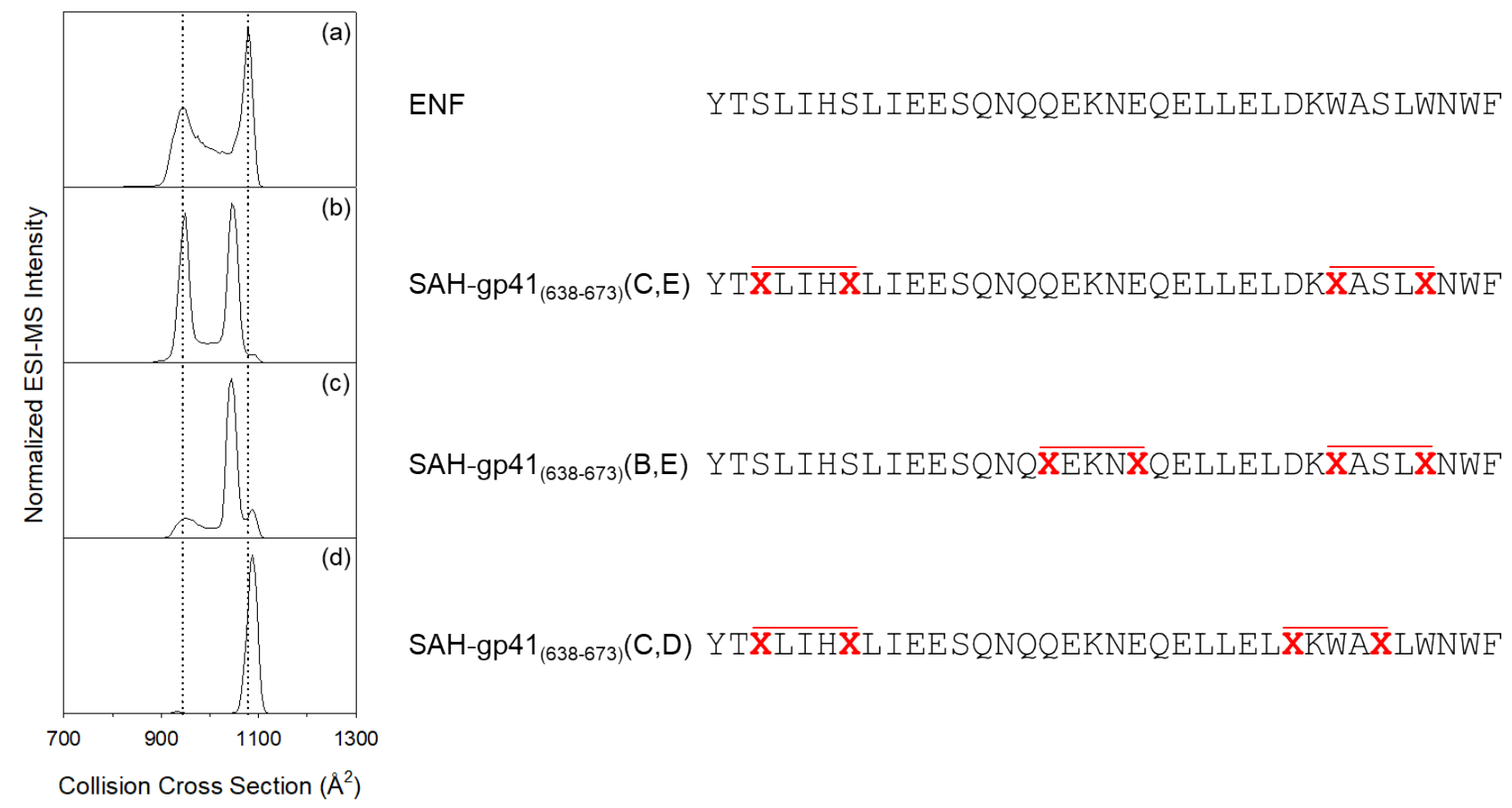

Figure S3. Collision cross section distributions ( $\left.{ }^{T W} C C S D_{N 2}\right)$ for $(a)$ native ENF and (b-d) doublestapled constructs. Vertical dotted lines are meant to facilitate comparison with peak maxima observed in (a). Red lines above peptide sequences indicate $i, i+4$ hydrocarbon staples between non-native residues $(X)$. 

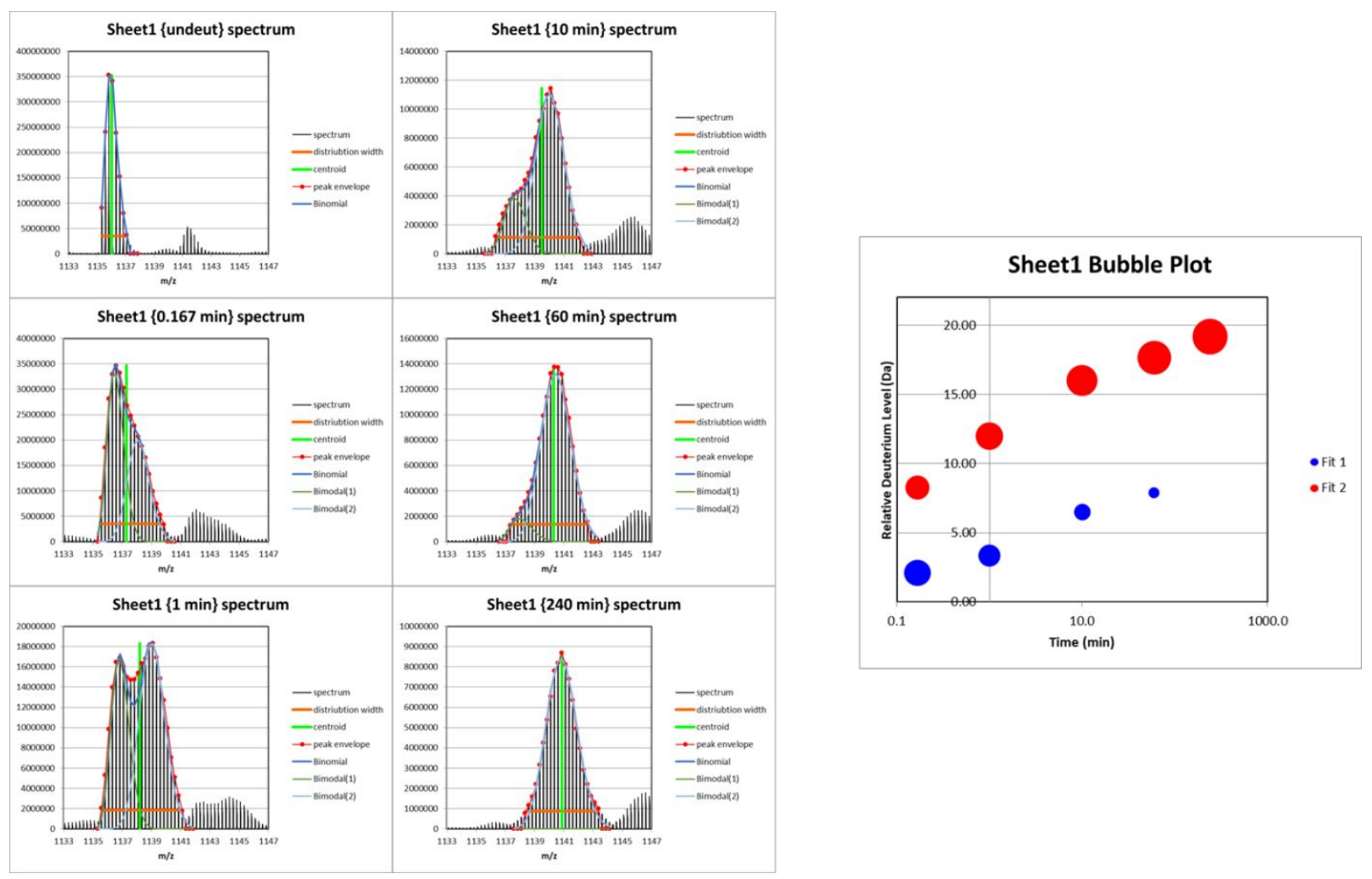

Figure S4. Isotopic envelope fitting from HXExpress for the temporal deuterium uptake of the SAH-gp41 ${ }_{(638-673)}(\mathrm{D})$ construct. Also shown is the bubble plot, indicating the relative abundances of the low- and high- $\mathrm{m} / \mathrm{z}$ populations as a function of exchange time. Under the labeling conditions used here, the theoretical maximum deuterium uptake is $30.24 \mathrm{Da}$. 


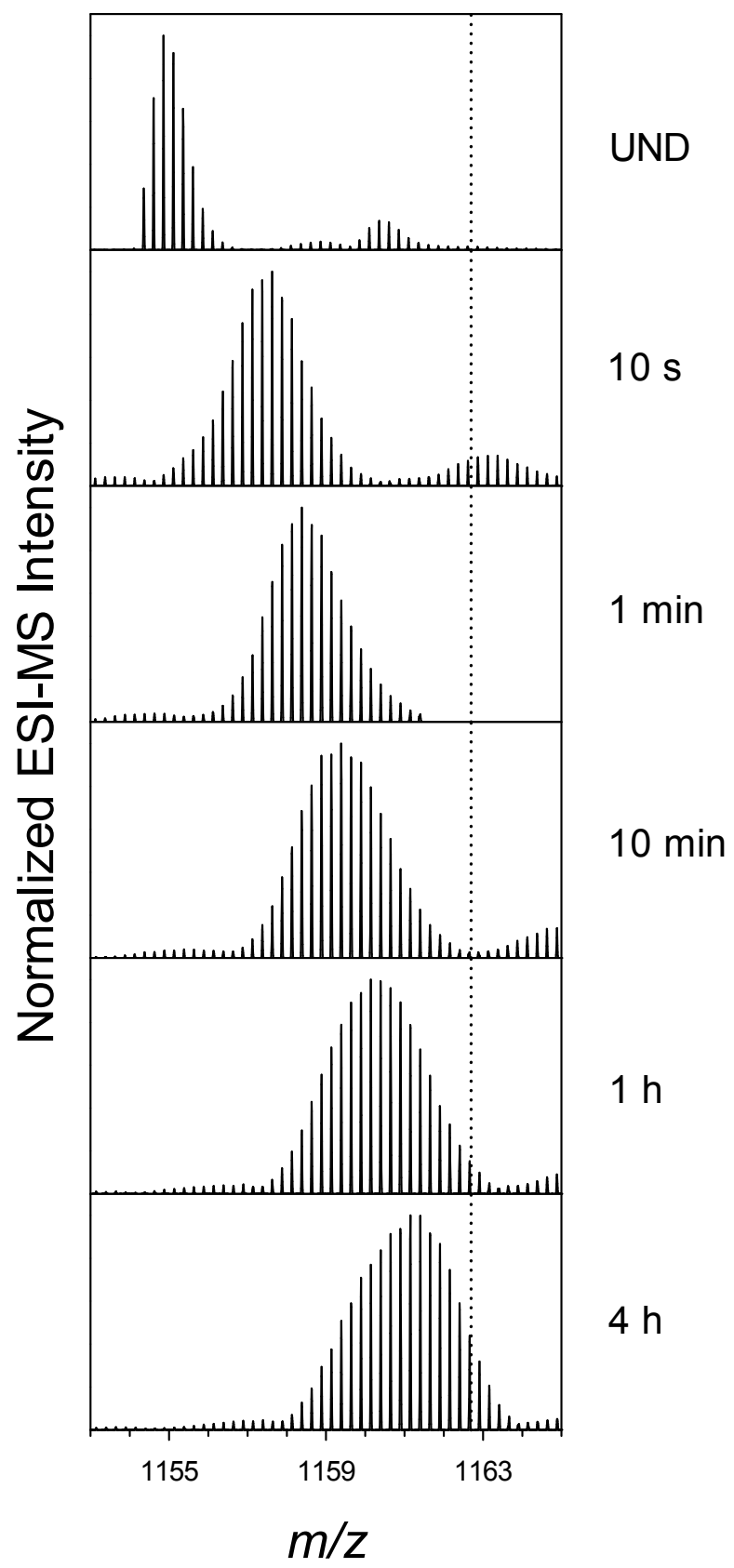

Figure S5. $m / z$ spectra of SAH-gp41 $1_{(638-673)}(\mathrm{C}, \mathrm{D})$ double-stapled Enf construct with increasing deuterium exchange time. Vertical dotted line represents the centroid of the theoretical maximally-labelled peptide. 


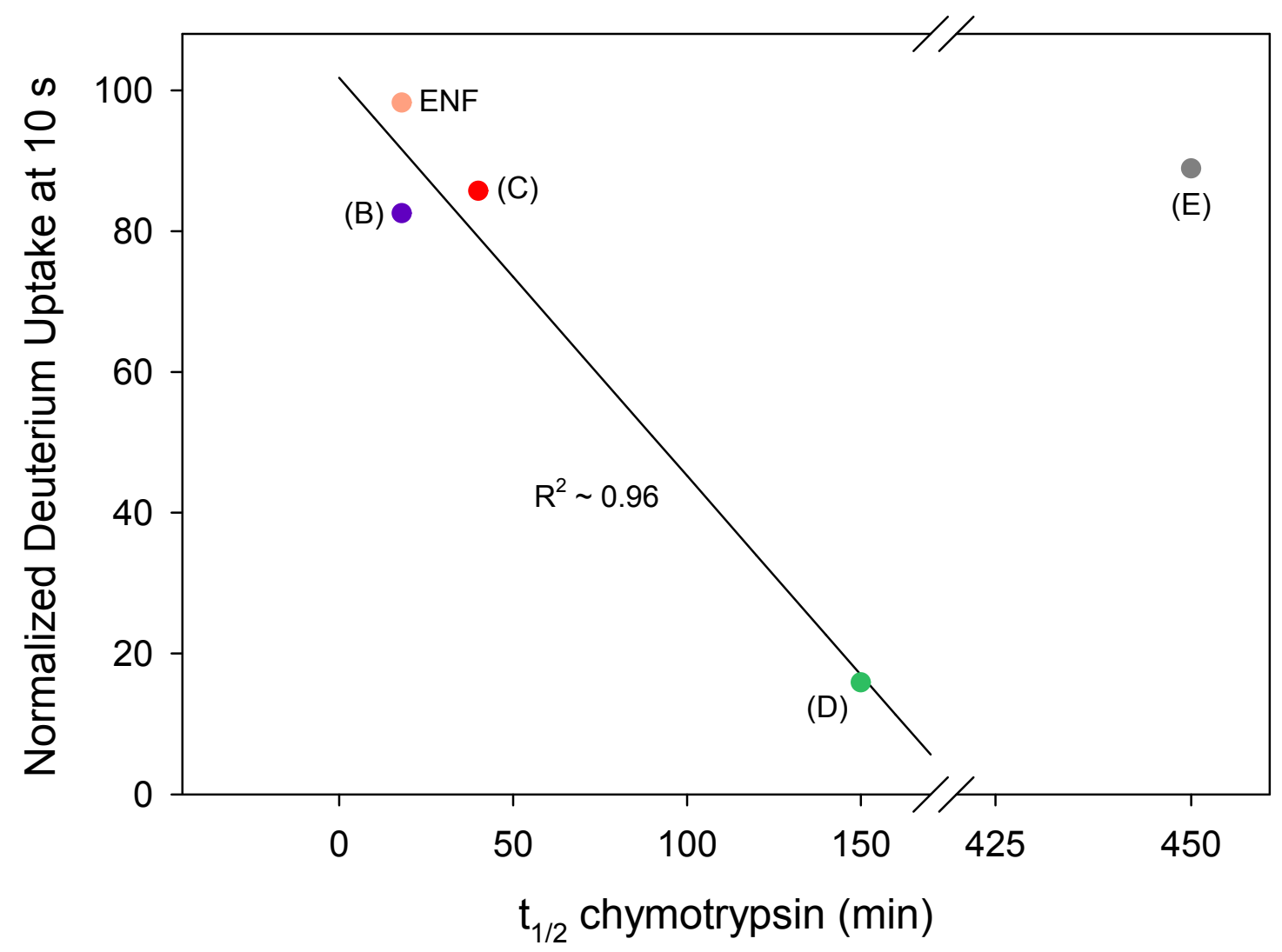

Figure S6. Relationship between deuterium uptake at $10 \mathrm{~s}$ and resistance to chymotrypsin digestion for native Enf and single-stapled SAH-gp41 ${ }_{(638-673)}$ constructs. Lettering refers to staple positioning as defined in Table 1 in the main text. Linear regression omitted construct $(E)$. 